\title{
Inhibition of Angiotensin Converting Enzyme (ACE) in Salt Receiving Fat-Fed Rats is Associated with Decreased Renal Oxidative Stress and Restoration of Neuronal Nitric Oxide Expression
}

\author{
Olfat Shaker M.D., Samah El Attar M.D., Laila Ahmed El Said M.D., \\ Sandra M. Younan M.D., Mary A. Youssef M.D. \\ Departments of Medical Biochemistry and Physiology, \\ Faculty of Medicine, Cairo University.
}

\begin{abstract}
Impaired renal sodium excretion has been observed in fat induced obesity and was claimed to be multifactorial. Interestingly the subsequently developed hypertension can respond to one drug treatment, the angiotensin-converting enzyme inhibitor (ACE-I), suggesting a relationship between different causes of such impaired renal sodium excretion. This study aimed to elucidate such relationship and included six groups; group 1: rats fed the standard chow, group 2: moderately high fat diet (MHFD) fed rats, group 3: high salt fed (HSD) rats (4\% Nacl for 1 week), group 4: $M H F D+H S D$, group 5: HSD $+A C E-I$ and group 6: MHFD $+H S D+A C E-I$. It was found that 10 weeks of MHFD significantly increased the obesity index in groups 2, 4 and 6 compared to groups 1, 3 and 5 respectively and the systolic blood pressure in response to HSD in group 4 compared to group 3. Moreover MHFD led to significant albuminuria with significant reduction in urinary sodium excretion. Also MHFD increased significantly the renal malondialdehyde level (MDA) as an index of oxidative stress and angiotensinogen $(A G)$ gene expression with significant decrease in urinary nitrites excretion and renal neuronal nitric oxide synthase (nNOS) expression in group 2 compared to group 1 and in group 4 compared to group 3. While HSD for one week did not have an impact on these previous parameters as evident by their non-significant differences between groups 3 and 1 and between groups 4 and 2. However, ACE inhibition in group 6 decreased significantly its urine albumin content, renal $A G$ and MDA and significantly increased its urinary Na and nitrites excretion as well as its renal nNOS compared to group 4. Also ACE-I improved renal $A G$ and $n N O S$ in group 6 to be insignificantly different from those of group 5. These previous results suggest that a link coexist between renal angiotensinogen upregulation and renal oxidative stress mediated decrease in NO availability. In conclusion the MHF fed rats exhibited salt sensitivity accompanied by upregulation of renal angiotensinogen expression, increased oxidative stress and decreased nNOS expression, all of which could contribute to salt retention and hypertension.
\end{abstract}

Key words: $n N O S$, sodium excretion, oxidative stress. 


\section{INTRODUCTION}

Obesity is one of the health conditions which is associated with several central and peripheral abnormalities that can explain the development or maintenance of high arterial blood pressure. Dramatic advances in understanding the mechanisms of obesity-related hypertension have been accomplished in recent years. Animal experiments and human studies revealed that the kidney is a key organ of the cardiovascular homeostasis and a high-fat diet consistently results in enhanced sodium reabsorption by the kidneys and ultimately increased risk of elevated blood pressure especially in salt sensitive individuals ${ }^{1,}$. Interestingly, weight loss in the same individual promotes urinary sodium excretion, demonstrating a direct link between body mass index and sodium retention $^{3}$. Conceptually, salt sensitivity is defined as an increase in blood pressure in response to increased sodium ingestion and/or a decrease in blood pressure when sodium intake is reduced, with the degree of change exceeding that attributed to directionally appropriate random blood pressure variation. Salt sensitivity results from alterations in kidney function that requires higher arterial pressure to maintain "steadystate" homeostasis ${ }^{4}$.

High fat intake-induced obesity is associated with several alterations in renal structure, reduced activity of arachidonic acid pathways in renal tubular sites, increased renal sympathetic nervous system activity ${ }^{6}$, activation of the rennin-angiotensin system $\left(\right.$ RAS $^{7}$ as well as a hyperinsulinemia ${ }^{8}$;all of which may contribute to sodium reabsorption and associated fluid retention and may therefore contribute to renal obesity hypertension ${ }^{9,10}$

Moreover high fat-diet causing insulin resistance may also induce salt sensitivity $^{11}$ as well as a functional NO deficiency ${ }^{12}$. The decrease in the production of nitric oxide (NO) leading to elevation of blood pressure is not only linked to endothelial dysfunction $^{13}$, but it was also demonstrated that the inhibition of its synthesis by the administration of NG-nitro-L-arginine methyl ester (LNAME), produces a marked vasoconstriction $^{14}$, sodium retention, and thereby a sustained increase in mean arterial blood pressure ${ }^{15}$. In fact, the tubuloglomerular feedbackmediated afferent arteriolar vasoconstrictive response to luminal sodium concentration is attenuated by NO derived from neuronal nitric oxide synthase (nNOS) in the macula densa. Moreover, pharmacological inhibition of nNOS has been reported to confer salt sensitivity in experimental animals $^{\mathbf{1 6}}$ and to augment the tubuloglomerular feedback response ${ }^{17}$. Also a relationship between a decrease in $\mathrm{NO}$ and oxidative stress (OXST) was identified by Beckman et al. ${ }^{\mathbf{1 8}}$ who reported that NO could combine with superoxide with a high degree of affinity to form peroxynitrite with potent oxidative properties. Furthermore, the administration of large doses of ANG II to rats induced an increase in both blood pressure and the formation of superoxide from isolated aortic strips.

It was reported also, that in the normotensive animal, dietary sodium 
loading results in increased NO production and decrease of RAS activity, which facilitates natriuresis and preserves blood pressure homeostasis $^{19,20}$. On the other hand, study on frank obese zucker rats, showed an inappropriately small natriuretic response to a saline load at mean arterial or intraglomerular pressure and was referred to as impaired pressure natriuresis ${ }^{21}$.

All these findings raise an important question whether similar renal changes can occur in a model of moderately high fat feeding and whether there is an existing relationship between renal angiotensin II, OXST, and NO in the regulation of renal sodium excretion and ultimately blood pressure in such model.

Therefore, the present study aimed to investigate: 1) Alteration in renal angiotensinogen and nNOS gene expressions and ultimately of sodium excretion and blood pressure in a model of moderately high fat-fed rats compared to control rats following high salt intake. 2) The possibility that oxidative stress generated by renal interstitial angiotensin II is related to the fall in its nNOS and that blockage of the actions of angiotensinconverting enzyme (ACE), through the use of a specific inhibitor, can partly attenuate the production of oxidative stress radicals and subsequently can increase the synthesis of nNOS in these rat models.

\section{MATERIAL \& METHODS}

60 Male rats, weighing 150-180 $\mathrm{g}$, were housed individually in a cage in a temperature- $\left(22-24^{\circ} \mathrm{C}\right)$ and light- controlled room on an alternating 12:12 h light-dark cycle. All animals had free access to food and water. ${ }^{22}$

Half of these animals received standard chow: containing $6.5 \% \mathrm{Kcal}$ fat and the other half received moderately high fat diet (MHFD): containing $32 \% \mathrm{Kcal}$ as fat for 10 weeks. At the beginning of the $10^{\text {th }}$ week, animals were divided into the following groups ( $\mathrm{n}=10$ / group):

Group 1: Control group: receiving standard chow and $0.4 \% \mathrm{Nacl}$.

Group 2: MHFD group: receiving the MHFD and $0.4 \% \mathrm{Nacl}^{22}$.

Group 3: High Salt fed (HSF) group: receiving the standard chow, with concomitant addition of $4 \%$ Nacl during the last week ${ }^{23}$.

Group 4: Salt supplemented MHFD: receiving the MHFD concomitant with $4 \%$ Nacl during the last week ${ }^{23}$.

Group 5: Salt and ACE- inhibitor supplemented (ACE-I) group: receiving the standard chow with the addition of $4 \%$ Nacl and ACE inhibitor Captopril in a dose of 25 $\mathrm{mg} / \mathrm{Kg} /$ day during the last week ${ }^{24}$.

Group 6: Salt and ACE-inhibitor supplemented MHFD fed group: receiving the MHFD with the addition of 4\% Nacl and ACE-I Captopril in a dose of $25 \mathrm{mg} / \mathrm{Kg} /$ day during the last week.

Calculation of the obesity index. Body weights and body lengths (nasoanal) were measured initially and then weekly for calculation of the obesity index, which is equivalent to the body mass index in humans. It was calculated by dividing the body weight in grams by the square of the naso-anal length in centimeters ${ }^{22}$.

Blood pressure measurement. The systolic blood pressure was measured 
under conscious conditions at the beginning of the experiment and at its end (after 10 weeks), to monitor any diet-induced changes in blood pressure. Before measuring the systolic blood pressure, the body temperature of the rats had to be adjusted to $37^{\circ} \mathrm{C}$ using an incubator for 10 minutes. The body temperature was verified by colonic temperature measurement. The systolic blood pressure was assessed with the tailcuff method using the electrosphygmomanometer. The average of 3 pressure readings was recorded for each measurement while the animals were quietly resting ${ }^{22}$.

\section{Urine collection:}

24-h urine samples under fasting conditions were collected before the end of the experiment by placing animals in metabolic cages. Urinary albumin concentration was determined by TCA turbidimetric immunoassay kit (Mitsubishi Chemical, Tokyo, Japan).

Sodium concentrations in urine were measured using ion-selective electrode system (EL-ISE Electrolyte System, Beckman Instruments, Brea, CA).

The end products of $\mathrm{NO}$, nitrites, and nitrates $\left(\mathrm{NO}_{2}{ }^{-}\right.$and $\left.\mathrm{NO}_{3}{ }^{-}\right)$were estimated in 24 hour urine samples by reducing $\mathrm{NO}_{3}^{-}$to $\mathrm{NO}_{2}^{-}$using nitrate reductase (Roche) and $\mathrm{P}_{\text {-adenine }}$ nicotinamide (B-NADPH, Sigma), followed by nitrites quantification with the Griess reagent, as previously reported 25 using nitrate/nitrite colorimetric assay kit; Alexis Biomedicals, San Diego, CA.

Blood samples: Retro-orbital fasting blood samples were taken at the end of 10 weeks and serum was separated for assessment of renal function by measuring serum urea and creatinine with an autoanalyzer (Technicon RA1000, Bayer, Tarrytown, NY).

Sodium concentrations in serum were also measured using ion-selective electrode system (EL-ISE Electrolyte System, Beckman Instruments, Brea, CA).

\section{Renal tissue samples:}

Animals were then decapitated and kidneys were excised and each one was divided into two portions: one part was stored in RNA extraction solution for RNA extraction followed by RT-PCR for Angiotensinogen and nNOS gene expressions. The other part was homogenized in PBS then the supernatant was used for detection of malondialdehyde (MDA).

RT-PCR method for detection of Angiotensinogen and nNOS gene expressions:

RNA isolation: Total RNA was isolated from kidney tissues of each group using RNA extraction kit (Qiagen, Hilden, Germany). The integrity of isolated total RNA was examined by $1 \%$ agarose gel electrophoresis, and RNA concentration was determined by UV light absorbance at $260 \mathrm{~nm}$ (Beckman DU640, Brea, CA).

RT-PCR: Relative level of nNOS and Angiotensinogen mRNA expression was assessed in renal tissues by semi quantitative RT-PCR. Briefly, all primer sequences were custom obtained from GIBCO BRL (Gaithersburg, MD).Sense nNOS primer was 5'GAACCCCCAAGACCATCC-3' and antisense was 3'GGCTTTGCTCCCACAGTT-5', which amplified a fragment of 308 bp 
26. Sense angiotensinogen primer for rat was 5'-GCT TCT CCC AGC TGA CTG GG-3', and the downstream primer was 5'-GGT TGG TGT CAC CCA TCT TGC C-3'and the expected RT-PCR product was $404 \mathrm{bp}{ }^{27}$. RT was carried out using $2.5 \mu \mathrm{g}$ of total RNA from renal tissues. Before RT reaction, total RNA was heated at $65^{\circ} \mathrm{C}$ for $10 \mathrm{~min}$. RT was performed at $37^{\circ} \mathrm{C}$ for $60 \mathrm{~min}$ in a total volume of $20 \mu \mathrm{l}$ using $200 \mathrm{U}$ of the Moloney murine leukemia virus reverse transcriptase (GIBCO BRL), 100 pmol of random hexamers (GIBCO BRL), $0.5 \mathrm{mM}$ of each dNTP (Sigma, St. Louis, MO), and 1x RT buffer $(75 \mathrm{mM} \mathrm{KCl}, 50 \mathrm{mM}$ Tris $\cdot \mathrm{HCl}, 3 \mathrm{mM}$ $\mathrm{MgCl}_{2}, 10 \mathrm{mM}$ DTT, pH 8.3). Samples were heated at $95^{\circ} \mathrm{C}$ for 5 $\min$ to inactivate the reverse transcriptase and diluted to $40 \mu \mathrm{l}$ with PCR grade water. Ten $\mu$ l of RT individual samples of each group was used for nNOS or Angiotensinogen amplification in $20-\mu 1$ final volume reactions containing $1 \mathrm{x}$ PCR buffer (10 mM Tris $\mathrm{HCl}, 1.5 \mathrm{mM} \mathrm{MgCl}_{2}, 50$ $\mathrm{mM} \mathrm{KCl}, \mathrm{pH} 8.3), 0.1 \mathrm{mM}$ of each dNTP, $10 \mu \mathrm{M}$ of each primer, and one unit of Taq DNA polymerase (GIBCO, BRL). PCR cycles were performed in a DNA thermal cycler, with the following profile: denaturation $1 \mathrm{~min}$ at $94^{\circ} \mathrm{C}$; annealing $1 \mathrm{~min}$ at $55^{\circ} \mathrm{C}$ for $\mathrm{nNOS}, 58^{\circ} \mathrm{C}$ for angiotensinogen primers; and $1 \mathrm{~min}$ extension step at $72^{\circ} \mathrm{C}$. Last cycle was followed by a final extension step of 5 min at $72^{\circ} \mathrm{C}$. Control gene was coamplified simultaneously in each reaction. Bands were ethidium bromide stained and visualized under UV light. $\begin{array}{lcc}\text { Measurement } & \text { of } & \text { renal } \\ \text { malondialdehyde } & \text { (MDA) } & \text { level: }\end{array}$ Tissues were homogenized in $10 \mathrm{mM}$ PBS ( $\mathrm{pH} 7.4$ ) and centrifuged for 30 $\min$ at $4^{\circ} \mathrm{C}$. Protein concentrations were measured using a Pierce kit. Then the supernatants were tested for the Lipid peroxide content by measuring spectrophotometrically the amount of malondialdehyde ${ }^{28}$.

\section{Statistical Analysis:}

The results were analyzed using SPSS computer software package, version 10.0 (Chicago-IL, USA) ${ }^{29}$. Data were presented as mean \pm S.D. Differences among the parameters of the different groups were compared by one-way ANOVA. The results were considered statistically significant at $\mathrm{P} \leq 0.05$.

\section{RESULTS}

Table 1 reveals that the obesity index was significantly increased in group 2 compared to group 1, in group 4 compared to group 3 and in group 6 compared to group 5 following 10 weeks of MHFD intake.

When the obesity index was compared between rats fed standard chow, it significantly decreased in group 3 compared to group 1 and in group 5 compared to groups 1 and 3 .

Similarly when the obesity index was compared between the different MHFD fed rats groups (2, 4 and 6), there was a significant decrease in that of group 4 compared to that of group 2 and in that of group 6 compared to that of group 2 but without a significant decrease compared to group 4, indicating a decreasing effect of the high salt intake on the rats obesity index. 
The systolic blood pressure (SBP) showed an insignificant difference in group 2 compared to that of group 1 and in group 6 compared to group 5 , while it showed a significant increase in group 4 compared to that of group 3 indicating the effect of salt combined with MHFD in increasing the blood pressure and the improvement of the SBP when ACE-I was administered to MHFD rats.

Comparing the SBP between groups 1, 3 and 5, no significant difference was found denoting unchanged blood pressure response neither to salt alone nor to salt + ACE-I in the rats fed with the standard chow. While among the different weight gained groups, it revealed a significant increase in SBP in group 4 compared to group 2 pointing to the salt induced effect on the SBP. Also, SBP showed a significant decrease in group 6 compared to group 4 indicating that administration of ACE-I can reduce the SBP in MHFD fed rats in response to high salt intake.

Table 1: Obesity index, systolic blood pressure and kidney function tests in the studied groups.

\begin{tabular}{|c|c|c|c|c|c|c|}
\hline Groups & $\begin{array}{c}\text { Obesity } \\
\text { index }\left(\mathrm{g} / \mathrm{cm}^{2}\right)\end{array}$ & $\begin{array}{c}\text { SBP } \\
\text { (mmHg) }\end{array}$ & $\begin{array}{c}\text { Urine } \\
\text { Volume } \\
(\mathrm{ml} / 24 \mathrm{~h}) \\
\end{array}$ & $\begin{array}{c}\text { Urinary } \\
\text { Albumin/24 } \\
\text { h.(mg/24h) }\end{array}$ & $\begin{array}{c}\text { Serum Urea } \\
\text { (mg/dl) }\end{array}$ & $\begin{array}{c}\text { Serum } \\
\text { Creatinine } \\
(\mathrm{mg} / \mathrm{dl})\end{array}$ \\
\hline 1 & $0.42 \pm 0.01$ & $122 \pm 5.19$ & $737 \pm 141.5$ & $2.93 \pm 0.8$ & $73.1 \pm 2.33$ & $0.65 \pm 0.05$ \\
\hline 2 & $0.54 \pm 0.02 *$ & $120.9 \pm 8.2$ & $1572 \pm 287 *$ & $9.66 \pm 2.1^{*}$ & $89.1 \pm 2.37 *$ & $0.76 \pm 0.05^{*}$ \\
\hline 3 & $0.30 \pm 2.5 *$ & $117.4 \pm 5.2$ & $820 \pm 100.9$ & $2.08 \pm 0.41$ & $81.5 \pm 1.58 *$ & $0.74 \pm 0.005^{*}$ \\
\hline 4 & $0.45 \pm 0.03+\#$ & $132.2 \pm 8+\#$ & $1500 \pm 250.5 \#$ & $9.22 \pm 1.53 \#$ & $17.16 \pm 1.7+\#$ & $0.35 \pm 0.05+\#$ \\
\hline 5 & $0.25 \pm 0.04 * \#$ & $116 \pm 10.04$ & $1090 \pm 179.19^{*}$ & $1.71 \pm 0.31 * \#$ & $47.3 \pm 2 * \#$ & $0.75 \pm 0.05^{*}$ \\
\hline 6 & $0.38 \pm 0.04+\$$ & 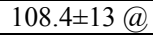 & 901土190.8+@ & 3.47/0.86+@\$ & $37 \pm 1.63+@ \$$ & $0.67 \pm 0.04+@ s$ \\
\hline
\end{tabular}

*: Significant compared to groupl at $P \leq 0.05$.

+: Significant compared to group 2 at $P \leq 0.05$.

\#: Significant compared to group 3 at $P \leq 0.05$.

@: : Significant compared to group 4 at $P \leq 0.05$.

\$: Significant compared to group 5 at $P \leq 0.05$.

Concerning the kidney function tests, table 1 reveals that there were statistically significant differences in serum urea and creatinine in groups 2 , 4 and 6 compared to groups 1, 3 and 5 respectively, but all these differences were within normal ranges. However, there was a significant increase in the $24 \mathrm{~h}$ urine volume and urinary albumin/24 h. in group 2 compared to 1 and in group 4 compared to 3 , while group 6 showed only a significant increase in urinary albumin compared to those of group 5 indicating that
MHFD is associated with renal dysfunction which was partly improved upon ACE-I administration.

High salt intake led to changes in kidney function tests which were within the normal ranges in group 3 compared to 1 and in group 4 compared to 2. While group 6 had a significant decrease in its $24 \mathrm{~h}$. urine volume and albumin content compared to groups 2 and 4 indicating improvement in renal function of MHFD rats upon ACE inhibition. 
Figure $1 \mathrm{~A}$ and $\mathrm{B}$ show that MHFD in group 2 was associated with a significant decrease in sodium excretion $/ 24 \mathrm{~h}$. urine associated with an insignificant change in its serum $\mathrm{Na}^{+}$when compared with those of group 1. Moreover, group 4 had a significantly decreased urinary $\mathrm{Na}^{+}$ excretion and subsequently a significant increase in its serum $\mathrm{Na}$ compared to group 3. Also group 6 had a significantly reduced sodium excretion compared to that of group 5 . Thus feeding rats with MHFD impaired renal sodium excretion.

Fig. 1A

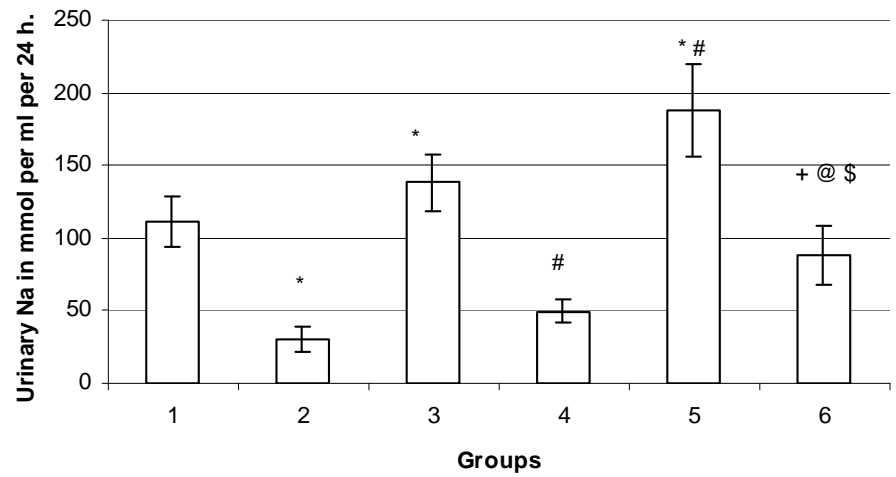

Fig.1B

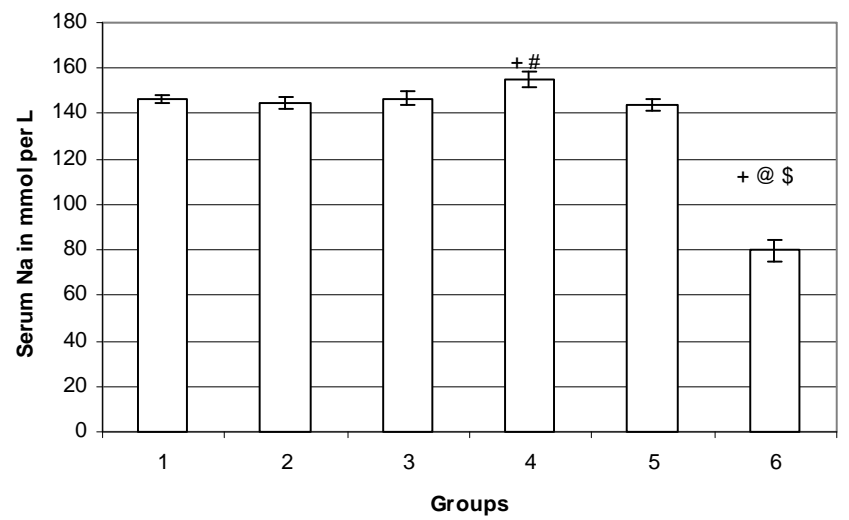

*: Significant compared to group1 at $P \leq 0.05$.

+: Significant compared to group 2 at $P \leq 0.05$.

\#: Significant compared to group 3 at $P \leq 0.05$.

@: : Significant compared to group 4 at $P \leq 0.05$.

\$: Significant compared to group 5 at $P \leq 0.05$.

Figure 1: Means of $24 \mathrm{~h}$. urinary sodium excretion (fig. A) and of serum sodium (fig. B) of the studied groups 
These results were associated with concomitant significant decrease in urinary nitrites excretion and in renal nNOS gene expression with a significant increase in renal angiotensinogen expression and MDA level in group 2 compared to group 1 and in group 4 compared to group 3 . Thus MHFD leads to impaired natriuresis, decreased NO production, increased renal oxidative stress with concomitant upregulation of renal angiotensinogen.

While group 6 compared to group 5 had a significantly decreased urinary nitrites excretion, a significantly increased renal MDA level and insignificantly different renal nNOS and angiotensinogen expression as revealed in figure $2 \mathrm{~A}, \mathrm{~B}$ and $\mathrm{C}$. These results indicate that inhibition of $\mathrm{ANG}$ II production can improve renal nNOS expression and decrease renal angiotensinogen expression in the MHFD receiving rats.

Figure $1 \mathrm{~A}$ and $\mathrm{B}$ revealed that group 3 compared to group 1 and group 5 compared to groups 1 and 3 had a significant increase in urinary sodium excretion without significant change in their $\mathrm{Na}$ serum level. Also they had a significantly increased urinary nitrite excretion without significantly changed renal nNOS and angiotensinogen gene expression and renal MDA level as shown in figure 2 $\mathrm{A}, \mathrm{B}$ and $\mathrm{C}$. Thus normally fed rats had natriuresis and increased $\mathrm{NO}$ production in response to salt intake without any further added effect of ANG II inhibition.

Comparing the results of the different weight gaining groups, it was found that group 4 compared to group 2 had insignificantly increased urinary $\mathrm{Na}$ excretion and a significantly increased serum $\mathrm{Na}$ level (fig.1 A and B). Also it had a significantly increased urinary nitrite excretion and insignificantly different renal nNOS and angiotensinogen expression and MDA level compared to group 2.

While group 6 showed a significant increase in its urinary $\mathrm{Na}$ and subsequently significantly decreased serum $\mathrm{Na}$ level compared to groups 2 and 4 (figure $1 \mathrm{~A}$ and $\mathrm{B}$ ). Moreover it showed a significant increase in its urinary nitrites excretion and in its renal nNOS gene expression. While it showed a significant decrease in its renal angiotensinogen and MDA level compared to the other MHF fed groups (fig. $2 \mathrm{~A}, \mathrm{~B}$ and $\mathrm{C}$ ). These results indicate that inhibition of angiotensin II production is related to reduction in the renal oxidative stress and to increased expression of renal nNOS in MHF salt fed rats. 
Fig.2A

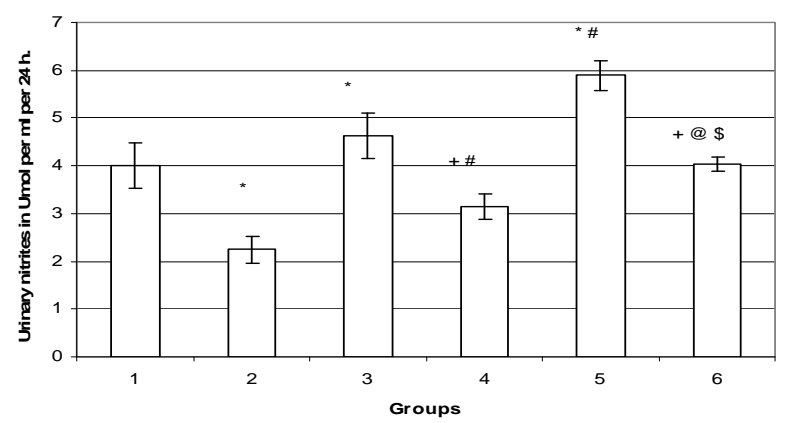

Fig.2B

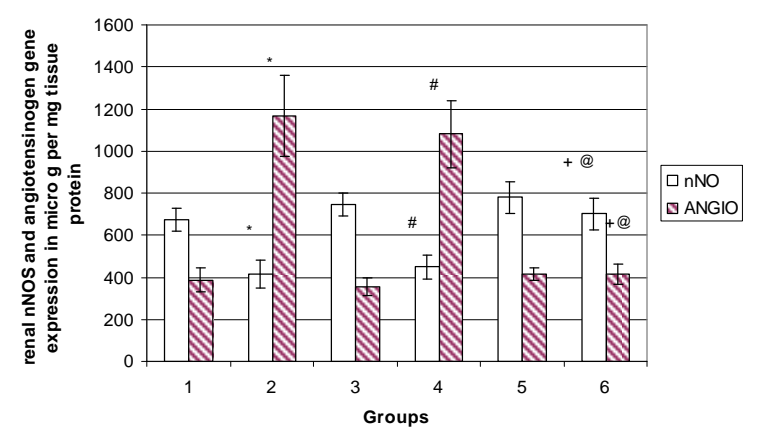

Fig. $2 C$

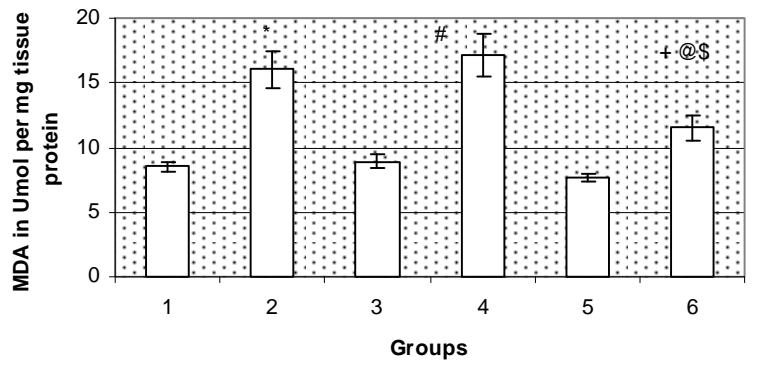

Figure 2: Means of 24 h. urinary nitrites excretion (fig. A), renal nNOS expression, renal angiotensinogen gene expression (fig. $B$ ) and renal malondialdehyde MDA level (fig. $C$ ) in the studied groups.

*: Significant compared to groupl at $P \leq 0.05$.

+: Significant compared to group 2 at $P \leq 0.05$.

\#: Significant compared to group 3 at $P \leq 0.05$.

@: : Significant compared to group 4 at $P \leq 0.05$.

$\$$ : Significant compared to group 5 at $P \leq 0.05$. 


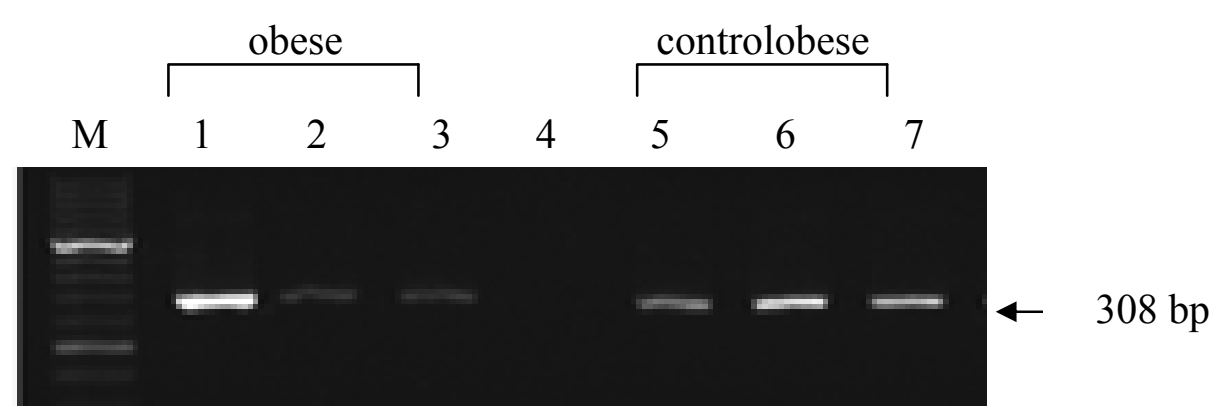

Figure 3: Aarose gel electrophoresis stained with ethidium bromide showing expression of nNOS gene at $308 \mathrm{bp}$.

M: DNA marker

Lane 1 group $6(M H F D+H S D+A C E-I)$

Lane 2 group $4(M H F D+H S D)$

Lane 3 group 2 (MHFD)

Lane 4 negative control

Lane 5 control

Lane 6 group 3 (HSD)

Lane 7 group $5(H S D+A C E-I)$

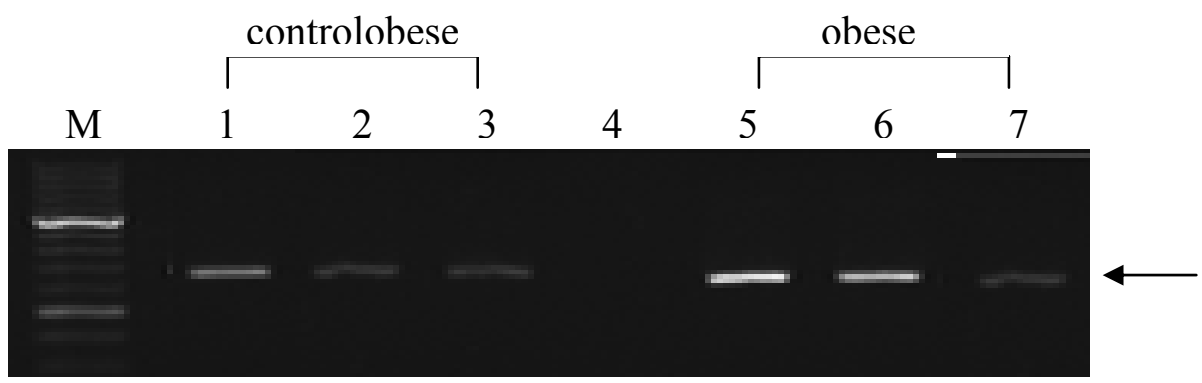

Figure 4 : Agarose gel electrophoresis stained with ethidium bromide showing expression of angiotensinogen gene at $404 \mathrm{bp}$.

M: DNA marker

Lane 1 group 5 (HSD + ACE-I)

Lane 2 group 3 (HSD)

Lane 3 control

Lane 4 negative control

Lane 5 group 2 (MHFD)

Lane 6 group 4 (MHFD + HSD) 
Lane 7 group $6(M H F D+H S D+A C E-I)$

\section{DISCUSSION}

Fat diet induced increased body weight and its related complications are very common. In this study, moderately high-fat diet (MHFD) increased significantly the obesity index in groups 2, 4 and 6 compared to their corresponding control groups 1,3 and 5 respectively. The MHFD used in this study contained $32 \% \mathrm{kcal}$ fat, as opposed to many other models that have very high levels of fat $(56 \%$ Kcal fat $)^{30}$. This explains why the increase in the obesity index was moderate and not enough to produce diet-induced obesity. High salt diet (HSD) decreased significantly the obesity index in group 3 compared to group 1, and in group 4 compared to group 2. This could be explained by the fact that HSD induces a significant increase in the leptin level which is well known to inhibit food intake ${ }^{31}$.

In the present study, neither the MHFD for 10 weeks (in group 2) nor the HSD for one week (in group 3) alone was able to induce hypertension. However, group 4 (MHFD + HSD) showed a significant elevation in the SBP when compared to either group 2 or 3 , suggesting that MHFD is responsible for the induction of hypertension in response to high salt intake, which is defined as salt sensitivity. Also, it is likely that increased salt intake is a necessary but not a sufficient cause for hypertension in this model and this agrees with previously published data demonstrating that $4 \% \mathrm{NaCl}$ induced a mild increase in SBP in obese prone rats but not in obese resistant ones ${ }^{32}$.
It has been established, that longterm regulation of mean arterial blood pressure (MABP) is intimately associated with extracellular fluid volume homeostasis, which itself is determined by sodium content, and the kidneys, as the principal route through which sodium is eliminated from the body, are therefore central to the long-term stability of MABP . However, a rise in MABP is matched by pressure natriuresis, which returns MABP to normal. Therefore, all forms of hypertension were predicted to be a consequence of abnormal pressure natriuresis responses ${ }^{33}$ BP homeostasis is sacrificed to preserve sodium balance.

Although the renal functions as serum urea and creatinine in groups 2 , 4 and 6 were significantly changed compared to groups 1,3 and 5 respectively, still they were within the normal ranges. Also, the rats in spite of being fasted, groups 2 and 4 had a significant increase in $24 \mathrm{~h}$. urine volume (to about $50 \%$ increase) and in urinary albumin $/ 24 \mathrm{~h}$ (more than 3 times increase) compared to groups 1 and 3 respectively, without a significant difference between renal functions of group 4 compared to group 2. This indicates that MHFD induced a significant renal damage independent of HSD. Thus this model of moderately high fat fed rats developed functional renal changes, salt sensitivity and became more liable to develop hypertension. Inhibition of ANG II production through the use of ACE-I in group 6, improved urinary albumin content and $24 \mathrm{~h}$ urine volume compared to groups 
2 and 4 although its albumin content was still significantly increased compared to group 5 indicating an impact of the ANG II on the MHFD induced renal dysfunction.

Albuminuria in MHFD fed rats could be ascribed to: increased reactive oxidative species $(\mathrm{ROS})^{34}$ since they have important pathogenic role in organ damage; to increased local ANG II, which can also cause renal damage via activation of transforming growth factor $\beta^{35}$ or enhancement of oxidative stress ${ }^{36}$; as well as to deficiency of NO renoprotective effect ${ }^{37}$.

Moreover, the results obtained in this study demonstrated that high salt intake is accompanied by a significant increase in the urinary $\mathrm{Na}^{+}$excretion without a significant change in serum $\mathrm{Na}^{+}$in groups 3 and 5 . On the other hand, an increase in obesity index was associated with a significant reduction of urinary sodium excretion (group 2 vs. group 1) even after sodium loading (group 4 vs. group 3) that leads to a significant elevation of serum $\mathrm{Na}^{+}$and SBP in group 4 compared to group 3 . This is consistent with decreased natriuretic ability reported in obese rats by several studies ${ }^{\mathbf{3 8}, 39}$. However, when ACE-I was administered in group 6 (MFD + HSD + ACE-I), it was able to significantly improve natriuretic capability (group 6 vs. group 4) and maintain SBP in its normal range, and this is apparently due to interference with the sodium retaining effect of ANG II.

Several clinical and experimental studies have demonstrated the phenomenon of salt-sensitive hypertension and impaired natriuresis in obesity, which were attributed to multiple mechanisms including abnormal regulation of the reninangiotensin system (RAS) ${ }^{\mathbf{4 0}}$, sympathetic nervous system activation $^{41}$, NO inactivation ${ }^{12}$ and impaired renal function ${ }^{42}$. It was also reported that increased production of NO results in renal vasodilation and both natriuresis and diuresis while a defect in the production of NO might be responsible for the salt sensitivity found in many hypertensive patients ${ }^{43}$. Also, ANG II is known to have a potent anti-natriuretic action, besides, although there is an uptake of ANG II from the plasma by the kidney, $\sim 85 \%$ of renal tissue ANG II originates from local production in the kidney ${ }^{44}$. Therefore, this study tested the hypothesis that the local renal RAS together with oxidative stress, that may be associated with moderately high fat diet, could have a remarkable effect on renal neuronal nitric oxide synthase (nNOS) and therefore they could influence the urinary sodium excretion.

A defect in total body NO can be explored by a significant reduction of urinary nitrite excretion. Renal NO is derived from all the 3 isoforms of NOS which are known to be expressed variably in different renal cells and reportedly contributes to the regulation of renal function. Inhibition of NOS activity within the kidney is known to lead to $\mathrm{Na}^{+}$retention and hypertension ${ }^{45}$. The precise role of each of the 3 NOS isoforms was not examined in this model of MHFD fed rats. However, since in the kidney, nNOS is expressed in the collecting duct, the efferent arteriole and mesangial cells with the highest expression in the macula densa cells ${ }^{\mathbf{4 6}}$ 
and given the great role of macula densa in regulating tubuloglomerular feedback (TGF) and sodium homeostasis, this study examined the effect of MHFD on the renal expression of nNOS and its relation to renal expression of angiotensinogen and OXST.

In the current study, salt sensitivity observed with MHFD (group 4) was associated with a significant reduction in urinary nitrite excretion and renal nNOS expression compared to group 3 . It should be noted that the reduction in urinary nitrite was unrelated to dietary nitrite/nitrate, as the rats were fasted during urine collection. Instead, it was most likely due to depressed NO production (depressed NOS), increased $\mathrm{NO}$ sequestration (increased ROS), or both. In contrast to MHFD rats, the chow-fed rats exhibited resistance to HSD (group 3), as evidenced by a lack of change in arterial pressure, despite high salt intake. This resistance was accompanied by a significant increase in urinary nitrite excretion and insignificant increase in renal nNOS expression compared to group 1 . These observations point to the role of MHFD in decreasing renal NO availability. Treatment of group 6 with ACE-I was accompanied by a significant increase in $\mathrm{NO}$ availability in comparison to group 4. However, on comparing group 6 with group 5, one can observe that ACE-I minimized the effect of MHFD as revealed by significant reduction in the urinary nitrite excretion without any significant change in the expression of renal nNOS. While, in absence of ACE-I, MHF diet had significantly reduced both the urinary nitrite excretion and the renal nNOS expression (group 2 vs. 1 and 4 vs.3). This latter observation could point to the possibility of an inhibitory effect of ANG II on the expression of renal nNOS.

In accordance with the present study results, previous studies have reported that higher fat diet (39\% Kcal Fat) fed animals exhibited a marked increase in nitrotyrosine (a marker of NO inactivation by ROS), pointing to increased NO inactivation $^{23}$ or had a significant decrease in renal NO production ${ }^{43}$. Also, NO produced by the macula densa was documented to attenuate TGF-mediated afferent arteriolar vasoconstriction in response to the luminal salt content ${ }^{47}$. Thus downregulation of renal $\mathrm{nNOS}$ or ROS-mediated inactivation of $\mathrm{NO}$ can promote salt sensitivity by augmenting the TGF response and diminishing pressure natriuresis ${ }^{23}$. Moreover, $\mathrm{Ni}$ et al. $^{\mathbf{4 8}}$ showed that increases in dietary salt for 3 weeks increased NO production in saltresistant, but not salt-sensitive, Dahl rats, suggesting that decreased NO production may cause salt-sensitive hypertension. Similar result was reported by Mattson and Higgins ${ }^{49}$ in genetically normotensive SpragueDawley rats. Regarding the effect of ANG II on nNOS, Moreno et $\mathrm{al}^{50}$ reported a similar inhibitory effect of ANG II infusion for 3 days on the renal nNOS.

On the other hand, other studies were apparently at odds with the present study. For example, Vallon et al. ${ }^{51}$ had pronounced that blood pressure in nNOS knockout mice is 
normal, suggesting that NO derived from this source plays only a minor role in BP management. Noronha et al. ${ }^{52}$ concluded that in early obesity after 8 weeks of high fat diet, there was a significant increase rather than a reduction in basal NO. However, their evidence for an increase in whole-body NO production especially those derived from iNOS was dependent upon the elevated plasma and not urinary nitrate levels in obese mice. Moreover, Roberts et al. ${ }^{\mathbf{1 2}}$ had reported an initial rise (6 months) in the total renal NO production capacity followed by a decrease at 2 years after a high fat diet in rats. These conflicting data may be attributed to; different amount of fat given to the animals; differences in obesity index; differences in chronic regulation of expression and activity of the various NOS isoforms ${ }^{45}$.

Therefore, it appears that whenever there is an intact renal NO system in rats, HSD for one week doesn't increase blood pressure. While in the presence of defective NO metabolism, an increase in blood pressure is necessary to maintain sodium balance. This defect in renal NO system could be related to oxidative stress ${ }^{53}$ or abnormal RAS ${ }^{54}$ both can be modulated by high fat diet.

The finding that macula densa cells express both $\mathrm{nNOS}^{16}$ and a complete complement of NADPH oxidase components ${ }^{55}$ provoked the hypothesis that TGF responses are regulated by an interaction between $\mathrm{O}_{2}^{-}$and $\mathrm{NO}^{56}$. In addition to inactivating NO, ROS and their byproduct of interaction with NO, peroxynitrite, can oxidize and deplete tetrahydrobiopterin, an essential NOS cofactor, which can augment NO deficiency and oxidative stress ${ }^{57}$ Interestingly, peroxynitrate may contribute to mitochondrial superoxide production by enhancing the build-up of semi-ubiquinone ${ }^{58}$.

From the results of the present study it could be suggested that MHFD induced a significant increase in renal ROS production as evident from a significant increase in renal malondialdehyde (MDA) level (group 2 vs. group 1 and group 4 vs. group 3). While HSD for one week didn't alter renal MDA as evident from the insignificant change in renal MDA in group 3 compared to group 1 and in group 4 compared to group 2. ACE-I was able to significantly reduce it (group 6 vs. group 4), to a level comparable to that of group 1, suggesting that ANG II had a great role in production of renal ROS in response to MHFD. However, other factors could have a role in ROS production because there was still a significant increase in renal MDA level in group 6 compared to group 5 otherwise, ACE-I used in this study $(25 \mathrm{mg} / \mathrm{Kg} /$ day $)$ wasn't able to completely prevent the oxidative stress induced by ANG II.

The precise mechanism(s) whereby MHFD leads to increased production of ROS and subsequently to functional deficiency of renal NO remains to be elucidated but according to previous studies, it may be related to; increased local leptin production ${ }^{32}$, increased production of ANG II which has been shown to upregulate synthesis of NADPH oxidase subunits to produce superoxide ${ }^{44}$, also under oxidative 
tetrahydrobiopterin (BH4), a cofactor required for the NOS activity, can be oxidized to dihydrobiopterin (BH2). In this case, NOS will produce superoxide rather than $\mathrm{NO}^{36}$, making this another mechanism by which reactive oxygen species (ROS) can be produced and NO concentrations can be reduced. Moreover, superoxide reportedly may potentiate TGF by exerting a constrictor-like action directly on the afferent arteriole independent of local $\mathrm{NO}^{59}$.

In this study, whole-kidney mRNA by real-time RT-PCR for angiotensinogen was also measured. It was found that MHFD was responsible for the marked increase in renal angiotensinogen gene expression in group 2 and 4 in comparison to their corresponding control groups 1 and 3 respectively, while HSD for one week had totally no effect on its expression as revealed from insignificant change in its expression between group 3 and 1 and group 4 and 2. Again, ACE-I was effective in reducing the renal angiotensinogen gene expression, this could be explained by the fact that ROS has a stimulatory effect on the renal expression of angiotensinogen ${ }^{60}$ and since inhibition of ANG II can reduce renal ROS, it can abolish this stimulatory effect. Therefore, it can be speculated that a vicious circle exist: a decrease in NO availability upregulates ROS, which in its turn will increase renal angiotensinogen expression, the resulting increase in ANG II will further increase ROS and subsequently decreases nNOS.

The results of the current study were consonant with the finding reported by other studies in which they reported that transgenic mice carrying an additional rat angiotensinogen (Agt) gene have been shown to exhibit hypertension ${ }^{23,61}$ (because angiotensinogen is rate limiting in the mouse ${ }^{62}$, whereas knockout of angiotensinogen results in hypotension ${ }^{63}$.

Several studies have suggested that a balance between the synthesis of NO and the formation of ANG II is necessary for the appropriate modulation of renal function and blood pressure ${ }^{64,65}$. This concept has been well demonstrated, showing that most of the effect produced by NO synthesis inhibition are minimized or abolished by the simultaneous blockade of ANG II and, vice versa. Therefore, the effects of activation of a process that progressively inhibit $\mathrm{NO}$ are, in fact, produced by ANG II, whose antinatriuretic and vasoconstrictor effects are left unbalanced $^{66}$. A process that exhibits such characteristics is oxidative stress, because it has the ability to quench NO and decrease its concentration. However, oxidative stress also involves other pressor mechanisms ${ }^{67}$.

In conclusion, the MHF fed rats exhibited a significant rise in blood pressure with increased dietary salt intake, pointing to an acquired salt sensitivity mediated, at least in part, by a reduction in renal nNOS abundance and increased ROSmediated NO inactivation. This NO deficiency together with the possible upregulation of renal angiotensinogen expression would result in salt retention, volume expansion, increased renovascular resistance, and hypertension. 


\section{REFERENCES}

1. Facchini F.S., DoNascimento C., Reaven G.M., Yip J.W., Ni X.P. and Humphreys M.H. (1999): Blood pressure, sodium intake, insulin resistance, and urinary nitrate excretion. Hypertens. , 33: 1008-1012.

2. Ni Z., and Vaziri N.D. (2001): Effect of salt loading on nitric oxide synthase expression in normotensive rats. Am. J. Hypertens., 14: 155-163.

3. Hall J.E., Crook E.D., Jones D.W., Wofford M.R. and Dubbert P.M. (2002): Mechanisms of obesityassociated cardiovascular and renal disease. Am. J. Med. Sci., 324: $127-137$.

4. Luft F, Weinberger M. (1997): Heterogeneous responses to changes in dietary salt intake: The salt sensitivity paradigm. Am. J. Clin. Nutr. ; 65(suppl.):612S-617S.

5. Wang M.H., Smith A., Zhou Y., Chang H., Lin S., Zhao X., Imig J.D. and Dorrance A.M (2003): Downregulation of renal CYPderived eicosanoid synthesis in rats with diet-induced hypertension. Hypertens. , 42: 594-599.

6. Abate N.I., Mansour Y.H. and Arbique D. (2001): Overweight and sympathetic activity in black Americans. Hypertens., 38: 379 383.

7. Zhang R. and Reisin E. (2000): Obesity-hypertension: the effects on cardiovascular and renal systems. Am. J. Hypertens., 13: $1308-1314$.
8. Weyer C., Pratley R.E., Snitker, Spraul M., Ravussin E. and Tataranni P.A. (2000): Ethnic differences in insulinemia and sympathetic tone as links between obesity and blood pressure. Hypertens., 36: 531 537.

9. Engeli S., Negrel R. and Sharma A.M. (2000): Physiology and pathophysiology of the adipose tissue reninangiotensin system. Hypertens., 35: $1270-1277$.

10. Stern J.S., Gades M.D. and Wheeldon C.M. (2001): Calorie restriction in obesity: prevention of kidney disease in rodents. J. Nutrit. , 131: 913S -917S.

11. Barnard R.J., Roberts C.K., Varon S.M. and Berger J.J. (1998): Diet-induced insulin resistance precedes other aspects of the metabolic syndrome. J. Appl. Physiol. 84: 1311-1315.

12. Roberts C.K., Vaziri N.D., Wang X.Q. and Barnard R.J (2000): NO inactivation and hypertension induced by a highfat, refined-carbohydrate diet. Hypertens., 36: 423-429

13. Moncada S., Palmer R.M., and Higgs E.A. (1991): Nitric oxide: physiology, pathophysiology and pharmacology. Pharmacol. Rev., 43: 109-142.

14. Romero J.C., Lahera V., Salom M.G.and Biondi M.L. (1992): Role of the endotheliumdependent relaxing factor nitric oxide on renal function. J. Am. Soc. Nephrol., 2: 1371-1387.

15. Lahera V., Salom M.G., Guardiola F.M., Moncada S. and Romero J.C. (1991): Effects 
of NG-nitro-L-arginine methyl ester on renal function and blood pressure. Am. J. Physiol. Renal Fluid Electrolyte Physiol., 261: F1033-F1037.

16. Wilcox C.S., Welch W.J., Murad F., Gross S.S., Taylor G., Levi R. and Schmidt H.H. (1992): Nitric oxide synthase in macula densa regulates glomerular capillary pressure. Proc. Natl. Acad. Sc.i USA, 89: 11993-11997.

17. Majid D.S.and Navar L.G. (2001): Nitric oxide in the control of renal hemodynamics and excretory function. Am. J. Hypertens., 14: 74S-82S.

18. Beckman, J.S., Beckman T.W., Chen J., Marshall P.A. and Freeman B.A. (1990): Apparent hydroxyl radical production by peroxynitrite: implications for endothelial injury from nitric oxide and superoxide. Proc. Natl. Acad. Sci. USA, 87: 1620-1624.

19. Deng $X$. , Welch W.J. and Wilcox C.S. (1994): Renal vasoconstriction during inhibition of NO synthase: effects of dietary salt. Kidney Int., 46: 639-646.

20. MorrisseyJ. J. McCracken R., Kaneto H., Vehaskari M., Montani D. and Klahr S. (1994): Location of an inducible nitric oxide synthase mRNA in the normal kidney. Kidney In., 45: 998-1005.

21. Fujiwara K.; Hayashi K.; Matsuda H.; Kubota E.; Honda M.; Ozawa $\mathbf{Y}$ and Saruta T.(1999): Altered PressureNatriuresis in Obese Zucker Rats. Hypertens., 33:1470-1475.
22. Dobrian A.D., Michael J.D., Russell L.P. and Thomas J.L. (2000): Development of hypertension in a rat model of diet-induced obesity. Hypertens., 35: 1009-1019.

23. Roberts CK, Vaziri ND, Sindhu RK, Barnard RJ (2003): A high-fat, refined-carbohydrate diet affects renal NO synthase protein expression and salt sensitivity.

.Appl.Physiol.,94:941-946.

24. Henriksen E.J., Jacob S., Kinnick T.R., Youngblood E.B., Schmidt E.B. and Dietze E.G (1999): ACE inhibition and glucose transport in insulin resistant muscle: roles of bradykinin and nitric oxide. Am. J. Physiol. Regul. Integr. Comp. Physiol., 277: R332-R336.

25. Shultz PJ, Tolins JP (1993): Adaptation to increased dietary salt intake in the rat. J. Clin. Invest., 91:642 -650.

26. Roczniak A, Zimpelmann J, Burns KD (1998): Effect of dietary salt on neuronal nitric oxide synthase in the inner medullary collecting duct.Am. J. Physiol., 275:F46-F54.

27. Gabriely I., Yang X., Cases J., Ma X., Rossetti L., and Barzilai N. (2001): Hyperglycemia modulates angiotensinogen gene expression Am. J. Physiol. Regul. Integr. Comp. Physiol., 128 (suppl. 1): R795-R802.

28. Draper H.H. and Hadley $M$. (1991): Assessment of Malondialdehyde method. Enzymol., 186:421-430.

29. Norusis M.J. (1997): SPSS 7.5 Guide to data analysis, Simon and 
Schuster Company, Upper Saddle River. New Jersey.

30. Lin L., Martin R., Schaffhauser A.O. and York D.A. (2001): Acute changes in the response to peripheral leptin with alteration in the diet composition. Am J Physiol. Regul. Integr. Comp. Physiol., 280: R504-R 509.

31. Ren J. (2004): Leptin and hyperleptinemia - from friend to foe for cardiovascular function. J. Endocrinol., 181: 1-10.

32. Dobrian A.D., Schriver S., Lynch T. and Prewitt R. (2003): Effect of salt on hypertension and oxidative stress in a rat model of diet-induced obesity. Am. J. Physiol. Renal. Physiol., 285: F619-F628.

33. Tallam L.; Stec D.; Willis M.; da Silva A. and Hall J. (2005): Melanocortin-4 ReceptorDeficient Mice are not hypertensive or salt-sensitive despite obesity, hyperinsulinemia, and hyperleptinemia. Hypertens., 46:326.

34. Manning R., Tian N. and Meng S. (2005): Oxidative stress and antioxidant treatment in hypertension and the associated renal damage. Am. J. Nephrol., 25:311-317.

35. Mezzano S., Ortega $M$. and Egido J. (2001): Angiotensin II and renal fibrosis. Hypertens, 38:635.

36. Vasquez J., Hogg N., Martasek P., Karoui H., Pritchard K. and Kalyanaraman B. (1999): Tetrahydrobiopterin-dependent inhibition of superoxide generation from neuronal nitric oxide synthase. J. Biol. Chem., 274: 26736-26742.

37. Dutta U., Lane J., Roberts L., Majid S. (2006): Superoxide formation and interaction with Nitric Oxide modulate systemic arterial pressure and renal function in salt-depleted dogs. Exp. Biol. and Med., 231:269276.

38. Bickel C., Verbalis J., Knepper M., and Ecelbarger C. (2001): Increased renal Na-K-ATPase, $\mathrm{NCC}$, and $\mathrm{B}$-ENaC abundance in obese Zucker rats. Am. J .Physiol. Renal Physiol., 281: F639-F648.

39. Aneja A., El-Atat F., McFarlane S. and Sowers J.R. (2004): Hypertension and obesity. Cent.Progress in Hormone Research, 59:169-205.

40. Rocchini A.P. (2000): Obesity hypertension, salt sensitivity and insulin resistance. Nutr. Metab. Cardiovasc. Dis., 10: 287-294.

41. Johnson R.J., Gordon K., Suga S., Duijvestijn A., Griffin K. and Bidani A. (1999): Renal Injury and salt-sensitive hypertension after exposure to catecholamines. Hypert. , 34:151159.

42. Hall J., Brands M. and Shek E. (1996): Central role of the kidney and abnormal fluid volume control in hypertension. J. Hum. Hypertens. , 10: 633-639.

43. Campese V. (1994): Salt sensitivity in hypertension: renal and cardiovascular implications. Hypertens., 23: 531-550.

44. Reckelhoff J. and Romero J. (2003): Role of oxidative stress in angiotensin-induced 
hypertension. Am. J. Physiol. Regul. Integr. Comp. Physiol., 284(4):R893-R912.

45. Herrera M.; Garvin J. (2005): Hypertension highlights, recent advances in the regulation of nitric oxide in the kidney. Hypertens. , 45:1062.

46. Mullins L.J., Bailey $M$. and Mullins J.J. (2006): Hypertension, Kidney, and transgenics: A Fresh Perspective. Physiol. Rev., 86: 709-746.

47. Thorup C. and Persson A. (1996): Impaired effect of nitric oxide synthesis inhibition on tubuloglomerular feedback in hypertensive rats. Am. J. Physiol. Renal Fluid Electrolyte Physiol.: 271; F246-F252.

48. Ni, Z., Oveisi F. and Vaziri N. (1999): Nitric oxide synthase isotype expression in saltsensitive and salt-resistant Dahl rats. Hypertens. , 34: 552-557.

49. Mattson $D$. and Higgins $D$. (1996): Influence of dietary sodium intake on renal medullary nitric oxide synthase. Hypertens., 27: 688-692.

50. Moreno C., López A., Llinás M., Rodríguez F., López F.A., Nava E. and Salazar J. (2002): Changes in NOS activity and protein expression during acute and prolonged ANG II administration. Am. J. Physiol. Regul. Integr. Comp. Physiol., 282: R31-R37.

51. Vallon V., Traynor T., Barajas L., Huang Y., Briggs J., and Schnermann J. (2001): Feedback control of glomerular vascular tone in neuronal nitric oxide synthase knockout mice. J.
Am. Soc. Nephrol., 12: 15991606.

52. Noronha B., Li J., Wheatcroft S., Shah A. and Kearney $M$. (2005): Inducible nitric oxide synthase has divergent effects on vascular and metabolic function in obesity. Diabetes, 54:10821089.

53. Dobrian A., Davies M., Schriver S., Lauterio T., and Prewitt R. (2001): Oxidative Stress in a Rat Model of obesityInduced Hypertension. Hypertens., 37[part 2]:554-560.

54. Kouyama R., Suganami T., Nishida J., Tanaka M., Toyoda T., Kiso M., Chiwata T., Miyamoto Y., Yoshimasa Y., Fukamizu A., Horiuchi M., Hirata Y. and Ogawa Y. (2005): Attenuation of diet-induced weight gain and adiposity through increased energy expenditure in mice lacking Angiotensin II type 1a receptor. Endocrinol. , 146, (8): 3481-3489.

55. Chabrashvili T., Tojo A., Onozato M., Kitiyakara C., Quinn M., Fujita T., Welch W., and Wilcox C. (2002): Expression and cellular localization of classic NADPH oxidase subunits in the spontaneously hypertensive rat kidney. Hypertens., 39: 269-274.

56. Wilcox C. (2003): Redox regulation of the afferent arteriole and tubuloglomerular feedback. Acta Physiol. Scand., 179: 217223.

57. Wilcox CS (2005): Oxidative stress and nitric oxide deficiency in the kidney: a critical link to hypertension? Am. J. Physiol. 
Regul. Integr. Comp. Physiol., 289: R913-R935.

58. Dröge W. (2002): Free Radicals in the Physiological Control of Cell Function. Physiol. Rev., 82: 47-95.

59. Liu R., Ren Y., Garvin J. and Carretero O. (2004): Superoxide enhances tubuloglomerular feedback by constricting the afferent arteriole. Kidney Int., 66: 268-274.

60. Hsieh T., Zhang S., Filep J., Tang S., Ingelfinger $J$. and Chan J. (2002): High glucose stimulates angiotensinogen gene expression via reactive oxygen species generation in rat kidney proximal tubular cells. Endocrinol., (143);(8): 29752985.

61. Morimoto S., Cassell M., Beltz T., Johnson A., Davisson R. and Sigmund C. (2001): Elevated blood pressure in transgenic mice with brain-specific expression of human angiotensinogen driven by the glial fibrillary acidic protein promoter. Circ. Res., 89; 365372.

62. Kimura S., Mullins J., Bunnemann B., Metzger R., Hilgenfeldt U., Zimmermann F., Jacob H., Fuxe K., Ganten D. and Kaling M. (1992): High blood pressure in transgenic mice carrying the rat angiotensinogen gene. EMBO J., 11: 821-827.

63. Tanimoto K., Sugiyama F., Goto Y., Ishida J., Takimoto E,. Yagami K., Fukamizu A. and Murakami K. (1994): Angiotensinogen-deficient mice with hypotension. J. Biol .Chem., 269: 31334-31337.

64. Romero, J. and Reckelhoff J. (1999): Role of angiotensin and oxidative stress in essential hypertension. Hypertens., 34: 943-949.

65. Melaragno, M. and Fink G. (1996): Role of ANG II in hypertension produced by chronic inhibition of nitric oxide synthase in conscious rats. Am. J. Physiol .Heart Circ. Physiol., 271: H806H8.

66. Berthold H., Just A., Kirchheim H., Heimo H. (1999): Interaction between nitric oxide and endogenous vasoconstrictors in control of renal blood flow. Hypertens., 34:1254.

67. Just A., Olson A., Whitten C. and Adrendshort W. (2007): Superoxide mediates acute renal vasoconstriction produced by angiotensin II and catecholamines by a mechanism independent of nitric oxide. Am. J. Physiol. Heart Circ. Physiol., 292:83-92. 


\title{
مانع انزيم تحويل الأنجيوتنسين فى الفئران التى تغذت على دهون و ملح

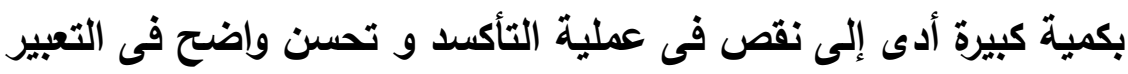

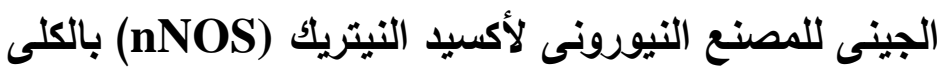

\author{
د. ألفت شاكر ، د. سماح العطار، د. لبليى أحدد، د. ساندرا بيونان، د. مارى يوسف \\ الملخص العربى
}

تتعدد أسباب عدم قدرة ألكلى على التخلص من الصوديوم فى حالات السمنة النى تتسبب فيها الدهون. وما يثير الأنتباه أن الضغط الناتج عن هذا بستجيب الى العلاج بعقار واحد وهو مانع انزيم تحويل الأنجيوتتسين مشيرا إلى وجود علاقة بين هذة الأسباب المتعددة.

يهدف هذا البحث إلى نوضيح هذة العلاقة ويشمل سنة مجموعات؛ المجموعة الأولى: فئران تغذت التئن

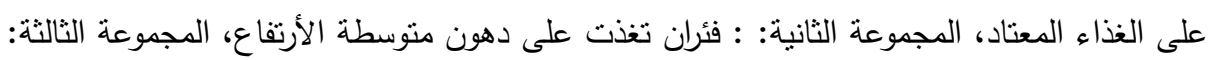

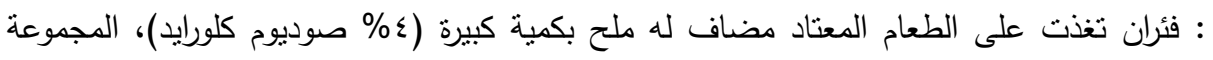

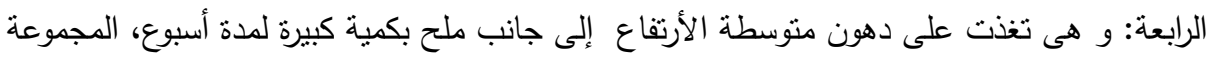

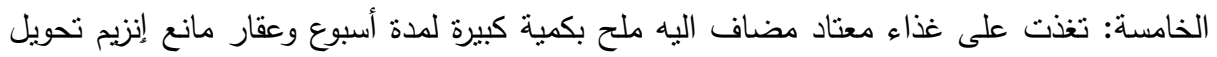

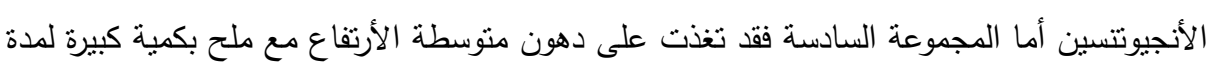
أسبوع وعقار مانع إنزيم تحويل الأنجيوتتسين. وجد فى هذا البحث أن الدهون متوسطة الأرتفاع أدت إلى زيادة لها دلالة إحصائية فى مؤشر السمنة للاجموعة الثانية و الرابعة و السادسة مقارنة بالمجموعة الأولى والثالثة و الخامسة على الترتيب. كما لإنا

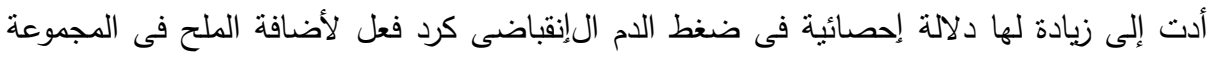

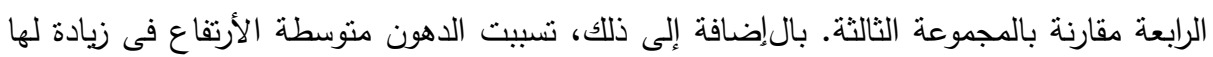

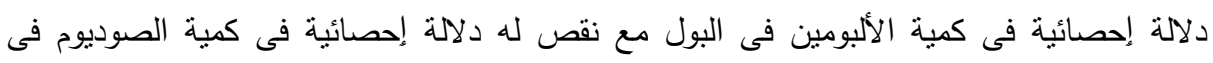

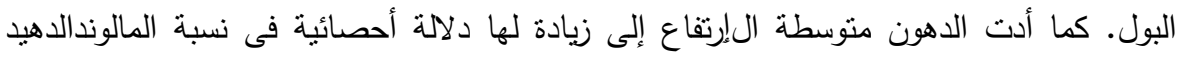
(MDA)

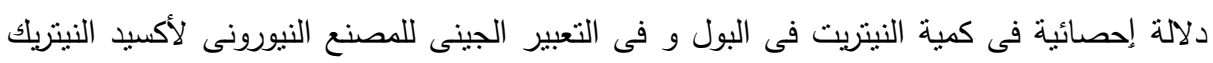
في المجموعة الثانية مقارنة بالمجموعة الأولى وفى الرابعة مقارنة بالثالثة. 
أضافة الملح بكمية كبيرة فى غذاء الفئران لمدة أسبوع لم يؤثر على القياسات السابقة كما تبين فى عدم

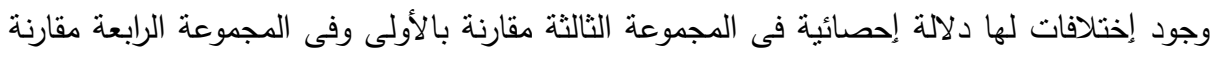

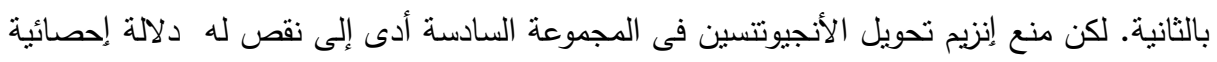

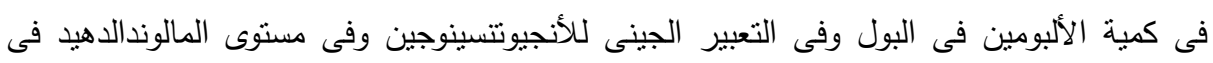

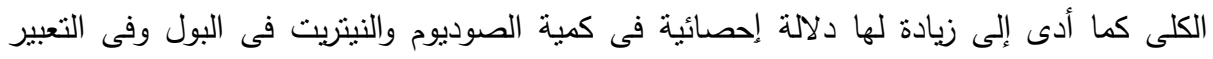

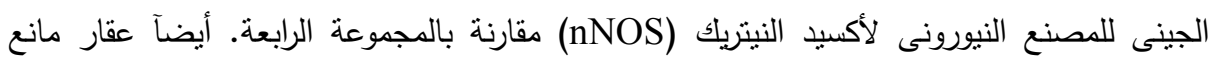

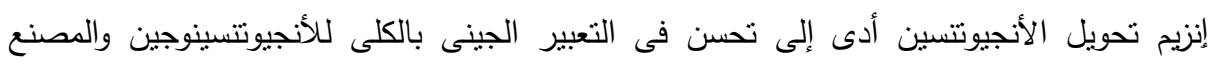

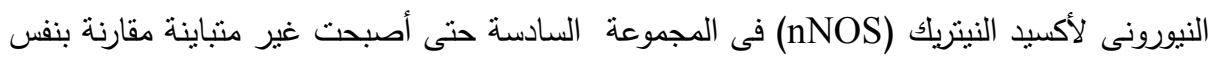

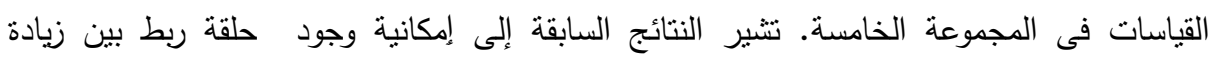
الأنجيوتتسينوجين فى الكلى ونقص أكسيد النيتريك المتاح نتيجة للتأكسد.

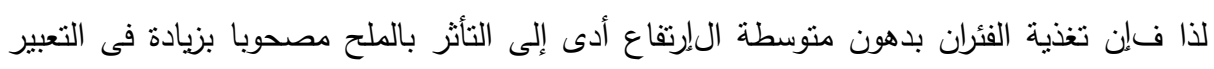

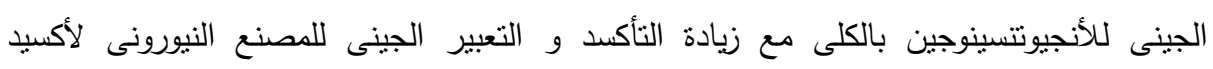

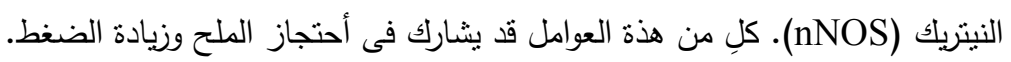

